\title{
Quality Study of Automated Machine Made Environmentally Friendly Brick (KAB) Sample Using Film Neutron Radiography Technique
}

\author{
Khurshed Alam ${ }^{1}$, Robiul Islam², Sudipta Saha ${ }^{1}$, Nurul Islam ${ }^{1}$, Syed Azharul Islam² \\ ${ }^{1}$ Institute of Nuclear Science and Technology, AERE, Savar, Bangladesh; ${ }^{2}$ Department of Physics, Jahangirnagar University, Savar, \\ Bangladesh. \\ *Corresponding author: alammk1964@yahoo.co.in
}

Received September $20^{\text {th }}, 2013$; revised November $24^{\text {th }}, 2013$; accepted December $6^{\text {th }}, 2013$

Copyright (C) 2013 Khurshed Alam et al. This is an open access article distributed under the Creative Commons Attribution License, which permits unrestricted use, distribution, and reproduction in any medium, provided the original work is properly cited. In accordance of the Creative Commons Attribution License all Copyrights (C) 2013 are reserved for SCIRP and the owner of the intellectual property Khurshed Alam et al. All Copyright (C 2013 are guarded by law and by SCIRP as a guardian.

\begin{abstract}
Neutron radiography (NR) technique has been adopted to study the internal structure and quality of the KAB bricks made by Hoffman kiln method. Thermal neutron radiography facility installed at the tangential beam port of $3 \mathrm{MW}$ TRIGA Mark-II Research Reactor, AERE, Savar, Dhaka, Bangladesh is used in the present study. Measurements were made to determine the internal structure and quality of the automated machine made environmentally friendly brick sample. In this case, optical density/gray values of the neutron radiographic images of the sample have been measured. From these measurements, the porosity, water penetrating height, water penetrating behavior, initial rapid absorption of water (IRA), elemental distribution/homogeneity and incremental water intrusion area in the sample have been found. From the observation of different properties, it is seen that, homogeneity of the Hoffman kiln brick KAB is not perfectly homogeneous and contains small internal porosity; the incremental water intrusion area is very poor, and the water penetrating height through the two edges is higher than the middle part; the initial rapid absorption (IRA) rate is also very poor and the water penetrating behavior of the samples is different as like as stair, capillary, wave and zigzag shape. From these points of view, it is concluded that the quality of the environmentally friendly brick KAB is better. The results obtained and conclusion made in this study can only be compared to the properties of bricks produced under similar conditions with similar raw materials.
\end{abstract}

Keywords: Neutron Radiography Technique; Water Penetrating Height/Behavior; IRA

\section{Introduction}

Neutron Radiography (NR) is a technique of making a picture of the internal details of an object by the selective absorption of a neutron beam by the object. NR uses the basic principles of radiography whereby a beam of radiation is modified by an object in its path and the emergent beam is recorded on a photo film (detector). In general, the radiography technique is nothing but a simple process of exposing some objects to an X-ray, gamma-ray, neutron beam and some other types of radiation and then attenuated outgoing beam from the object is passing through a special type of photographic film to form images of the objects on the radiographic film or detector. Also it is called a non-destructive testing (NDT) [1] and evaluation technique of testing non-nuclear and nuclear materials and industrial products. NR is an imaging technique which provides images similar to X-ray radiography and complementary technology for radiation diagnoses. Neutron radiograph gives the information of the internal structure of an object; it can detect light elements, which have large neutron absorption cross-sections like hydrogen and boron; it is completely complementary to other NDT techniques, like X-ray or gamma-ray radiography. The atoms of the object material scattered or absorbed the radiation and so the beam reaching the detector shows an intensity/gray value pattern representative of the internal structure of the object [2]. Any in-homogeneity in the object on an internal defect (such as voids, 
cracks, porosity, inclusion, corrosion etc.) and morphological change in the plant pod seeds [3] will show up as change in gray value/radiation intensity reaching the detector. Under these techniques, detecting faults in neutron shielding materials, flow visualization: real time neutron radiography, quality control of explosive devices, defects in ceramics materials, aircraft component, surface corrosion on aluminum, medical and biological applications, investigations of the root soil system, migration/rising of water in various building products/building materials, physical description of water transport in a porous matrix of the sample material, density fluctuations and porosity detection in ceramics etc [4-20]. Clay is a widely available raw material that survives very well in its fired form. Clay brick has been found in the ruins of ancient civilizations [21]. Bhatnagar et al. saw that properties of these bricks are affected as a result of physical, chemical and mineralogical changes $[22,23]$. Mbumbia et al. investigated that compressive strength and water absorption are two major physical properties of brick that are good predictors of bricks ability to resist cracking of face [24]. Few scientists studied that compressive strength is highly affected by firing temperature method of production, and physical, chemical and mineralogical properties of the raw material $[22,25]$. Water absorption is a measure of available pore space and is expressed as a percentage of the dry brick weight. It is affected by properties of clay, method of manufacturing and degree of firing. Some of the researchers studied that firing shrinkage increases with higher temperatures [26]. The quality depends on the firing temperature and firing time also. Decreasing firing temperature and shortening firing time do not only reduce the cost of production but also increase the productivity of the factory.

Environmental concerns have been raised in some parts of the world where coal is the main power generating sources and where bricks are also the main building material. Most of the scientists believe that fly ash on its own can be an excellent raw material for brick making. This has now been proven and a patent is taken for the manufacture of bricks from fly ash [27].

Many ancient cultures have made useful decorative items such as pottery, figurines, building tiles, and burial containers that become important parts of the archaeological record. The material aspects of clay and ceramic technology, the physical properties of clay and various firing methods can be investigated using archaeometric techniques $[28,29]$. Properties of bricks are affected as a result of physical, chemical and metrological changes $[23,30]$. Water absorption is a measure of available pore space and is expressed as a percentage of the dry brick weight. It is affected by properties of clay, method of manufacturing and degree of firing. Water absorption capacity of the brick affects the surface finishing of the brick-laid wall [21,26,31]. Ancient technologists and archaeological material researchers have employed standard techniques such as X-ray radiography, X-ray diffraction (XRD), scanning electron microscopy (SEM), and neutron activation analysis (NAA) to study structure and composition of ceramic materials [28,29]. Neutron radiography has been used to detect internal defects in some materials such as ceramics [9], tiles [10] and different building industries [11]. The technique is also adopted for the study of water absorption behavior in biopol, jute-reinforced-biopol composite [12] and wood plastic composites [13] etc. In the present work, neutron radiography technique has been adopted to the determination of elemental distribution/homogeneity, porosity, incremental intrusion area of water/water penetrating height and penetrating shape/behavior, and initial rapid absorption (IRA) of water in the sample as well as the quality of automated machine made environmentally friendly KAB brick.

\section{Experimental Facility}

The experimental neutron radiography facility installed at the tangential beam port of 3 MW TRIGA Mark II reactor in the Institute of Nuclear Science and Technology, Atomic Energy Research Establishment, Savar, Dhaka, Bangladesh. The neutron radiography facility consists of the following devices/equipment.

\subsection{Bismuth Filter}

In the NR facility at TRIGA reactor of BAEC a $15 \mathrm{~cm}$ long $\mathrm{Bi}$ filter in the tangential beam port is used to reduce the intensity of gamma ray significantly from the beam to prevent the unwanted fogginess in the radiographic image.

\subsection{Cylindrical Divergent Collimator}

A cylindrical divergent collimator made of $120 \mathrm{~cm}$ long aluminum hollow cylinder with $5 \mathrm{~cm}$ and $10 \mathrm{~cm}$ diameter at the inner and outer end, respectively, has been inserted in the tangential beam port to collimated neutron beam of the reactor. The advantage of the divergent collimator is that a uniform beam can be projected easily over a large inspection area. Collimators are required to produce a uniform beam and thereby produce adequate image resolution capability in a neutron radiography facility.

\subsection{Lead Shutter}

The outer end of the tangential beam tube is equipped with a lead-filled safety shutter and door to provide limited 
gamma shielding. The thickness of lead in the shutter is $24 \mathrm{~cm}$ and the diameter of the shutter is $33 \mathrm{~cm}$.

\subsection{Beam Stopper}

A wooden box with dimension of $68 \mathrm{~cm} \times 40 \mathrm{~cm} \times 68$ $\mathrm{cm}$ has been made with the attachment of four ball bearings on the bottom part of it for forward and backward movement in front of the tangential beam port. It looks a wooden box, which contains neutron-shielding materials like paraffin wax and boric acid in 3:1 ratio by weight for neutron shielding.

\subsection{Sample and Camera Holder Table}

There is a sample and camera holder table with both horizontal and vertical movement facility placed in front of the beam line.

\subsection{Beam Catcher}

To absorb transmitted and scattered neutron and gamma radiations a beam catcher with dimension $100 \mathrm{~cm} \times 100$ $\mathrm{cm} \times 85 \mathrm{~cm}$ has been placed behind the sample and camera holding table. A $30 \mathrm{~cm} \times 30 \mathrm{~cm} \times 30 \mathrm{~cm}$ hole has been made in the middle of the front face of the beam catcher which coincides with the central axis of the beam port. A $30 \mathrm{~cm} \times 30 \mathrm{~cm} \times 15 \mathrm{~cm}$ lead block weighing 125 $\mathrm{Kg}$ has been placed at the back side of the hole for gamma shielding. For neutron shielding a mixture of paraffin wax and boric acid has been used in the catcher. The total weight of the beam catcher is $968 \mathrm{Kg}$.

\subsection{Biological Shielding House}

The emitted neutron and the gamma rays are extremely dangerous for human body. This is why, to prevent these harmful rays to spread over the entire environment a biological shielding house has been built around the NR facility of the tangential beam port. It is made of special concrete containing cement, heavy sand (magnetite, ilmenite and ordinary sand) and stone chips in the ratio 1:3:3. Paraffin wax and boric acid in $3: 1$ ratio by weight were also used inside the biological shielding wall for neutron shielding. The width and height of the biological shielding wall of the facility are $\approx 3.0 \mathrm{ft}$ and $6.5 \mathrm{ft}$, respectively. Details of the NR facility can be found elsewhere $[3,32,33]$. The schematic diagram of the neutron radiography facility of $3 \mathrm{MW}$ TRIGA Mark II Reactor, AERE, Savar, Dhaka is shown in Figure 1.

\section{Experimental Procedure}

\subsection{Collection, Preparation and Size of the Sample}

Sample has been collected from Kapita auto bricks limited located at Joypura, Dhamrai, Dhaka, Bangladesh.

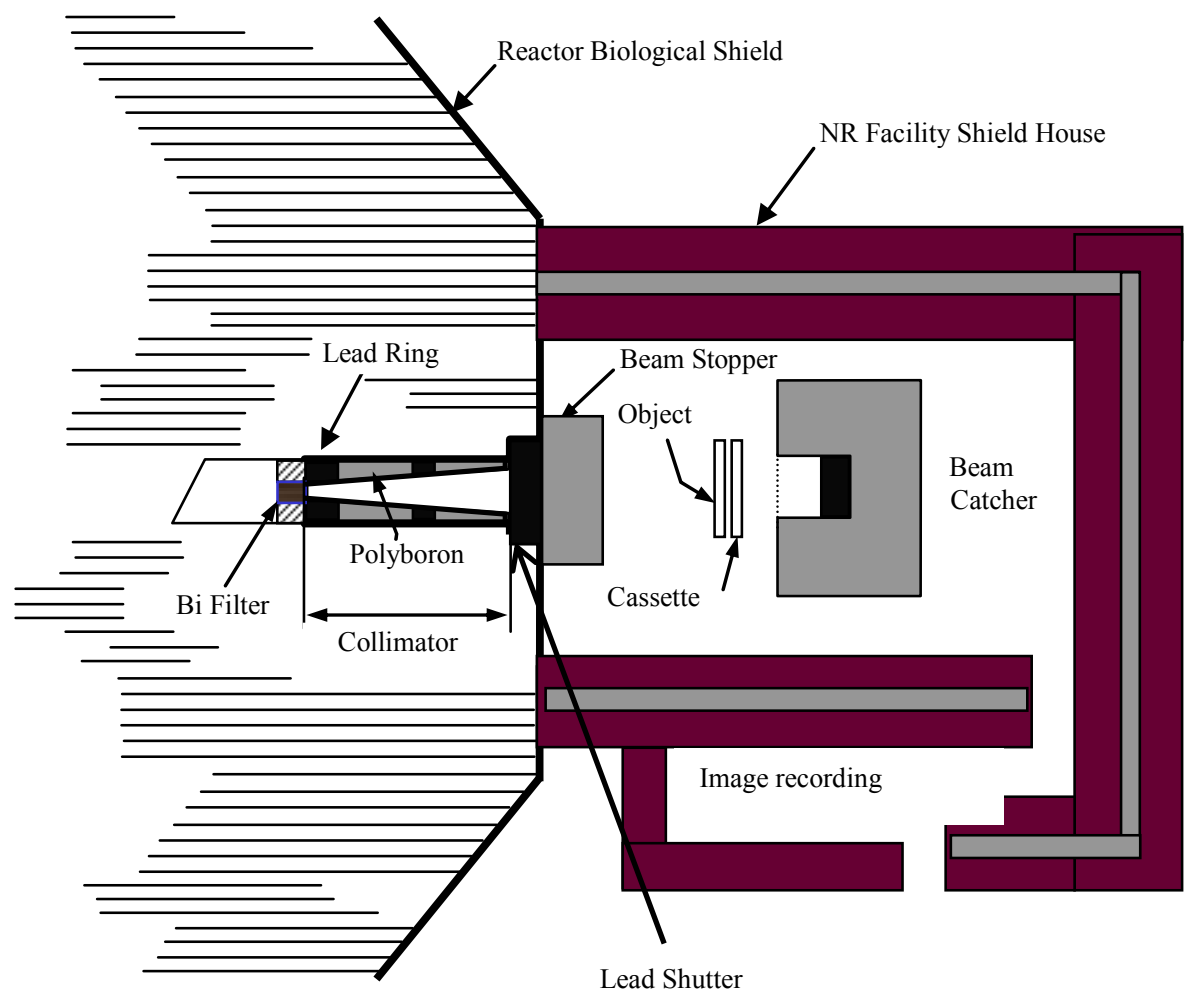

Figure 1. Schematic diagram of the neutron radiography facility. 
For final preparation, the sample is polished manually by using series paper, cement block, diamond cutter, and then the sample was dried at daylight/dryer machine until to get the constant weight. The sample is the rectangular shape and its size is $23.000 \times 11.360 \times 6.540 \mathrm{~cm}^{3}$ and $23.050 \times 10.821 \times 6.480 \mathrm{~cm}^{3}$ for KAB 1 and $\mathrm{KAB} 2$, respectively. In the case of KAB 2 sample, coal is mixtures with the soil and this coal is used to burn it. But in case of KAB 1 sample, coal is used into the brick kiln to burn the sample.

\subsection{Loading Converter Foil and Film in the NR Cassette}

A thin converter (gadolinium metal foil of $25 \mu \mathrm{m}$ thickness) was placed at the back of the X-ray industrial film. The loading of the X-ray industrial film (Agfa structurix $\left.\mathrm{D}_{4} \mathrm{DW}\right)$ into the NR cassette $(18 \mathrm{~cm} \times 24 \mathrm{~cm})$ is a simple procedure [14]. There are a number of steps to place the industrial X-ray film into the NR cassette to protect the film against daylight and lamplight.

\subsection{Placing of Sample and the NR Cassette}

The sample is placed in close contact with the NR cassette and directly on the sample holder table. The NR cassette is placed on the cassette holder table. Both of NR cassette and sample are placed in front of the neutron beam having $30 \mathrm{~cm}$ in beam diameter.

\subsection{Determination of Neutron Beam Exposure Time}

Exposure means passing of neutron beam through a sample and holding it onto a special film (X-ray industrial film) in order to create a latent image of an object in the emulsion layers of that film. Exposure time differs for different samples, depending on the intensity of the neutron beam, density and thickness of the sample and neutron cross-section. The optimum exposure time of the sample was determined by taking a series of experiments/radiographs at different exposure time, while the reactor was operated at $250 \mathrm{KW}$. For the present experiment we found the optimum exposure time is 60 minutes. The sample was then irradiated for that optimum time to obtain good neutron radiographs.

\subsection{Immersion Procedure of the Brick Sample}

The brick sample is placed in a plastic pan and a constant $2.0 \mathrm{~cm}$ height of water level is maintained. The water level is observed very carefully and adds extra water to maintain water level at $2 \mathrm{~cm}$ during the immersion time. After time of interest (TOI) such as 5, 10, 15 and 20 minutes brick sample take off from the pan and extra water of out side the sample is removed by using the tissue paper.

\subsection{Obtained Radiographic Images of the Sample}

\subsubsection{Irradiation}

While all the procedures (a-e) were performed, the neutron beam was disclosed by removing the wooden plug, lead plug and beam stopper from the front side of the collimator. Each sample was then irradiating for the optimum time $(60 \mathrm{~min})$ one by one at various immersion time.

\subsubsection{Developing}

Developing is an image processing technique by which the latent image recorded during the exposure of the material is converted into a silver image [34]. Developing process is completed at $20^{\circ} \mathrm{C}$ for 5 minutes.

\subsubsection{Fixing}

When the developing is completed a conventional photographic material must be treated in an acid stop bath or it must be rinsed in water, after which it is treated in a fixation bath. The fixation solution will dissolve the unexposed silver-halide crystals leaving only the silver grains in the gelatin. The fixing is completed with in 5 minutes and controls the fixture temperature at $20^{\circ} \mathrm{C}$.

\subsubsection{Washing}

In between developing and fixing the radiographic film, it is necessary to wash for 1 minute at flowing tap water.

\subsubsection{Final Washing}

The silver compound which was formed during the fixing stage must be removed, since they can affect the silver image at the latter stage. For this reason the film must be washed thoroughly in flowing tap water for $15 \mathrm{~min}$ utes after completion of developing and fixing process.

\subsubsection{Drying}

After the final washing, the films were dried by clipping in a hanger at fresh air/or in a drying cabinet.

After developing, washing, fixing and the final washing obtained radiographic images (Figures 2 and 3) of the required $\mathrm{KAB}$ brick sample at different immersion time.

\section{Mathematical Formulation}

\subsection{Optical Density Measurement}

The neutron intensity before reaching the brick sample (object) is different from the intensity of the neutron after passing through it. The relationship between these two intensities is expressed through the following equation [15] 


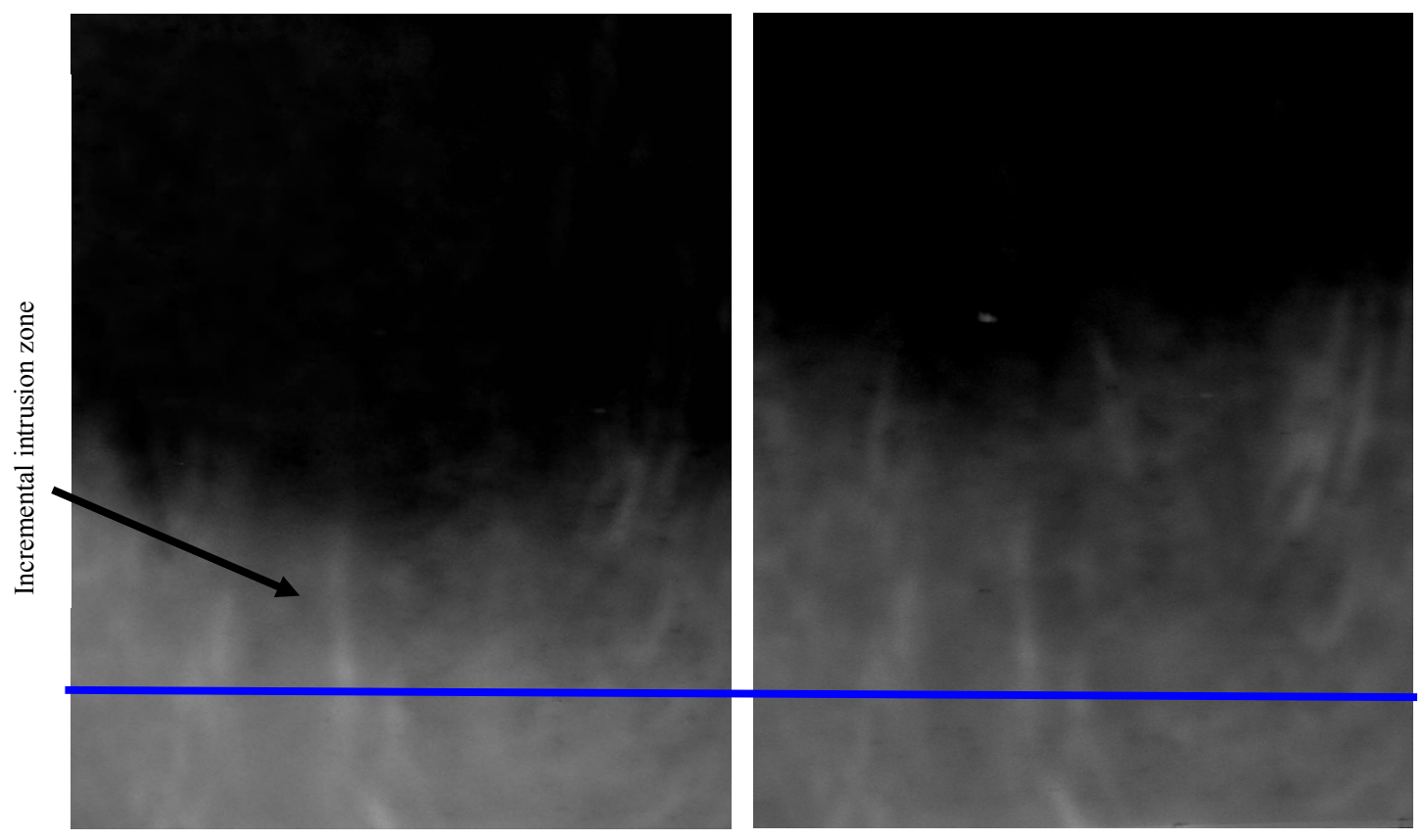

(a)

(b)

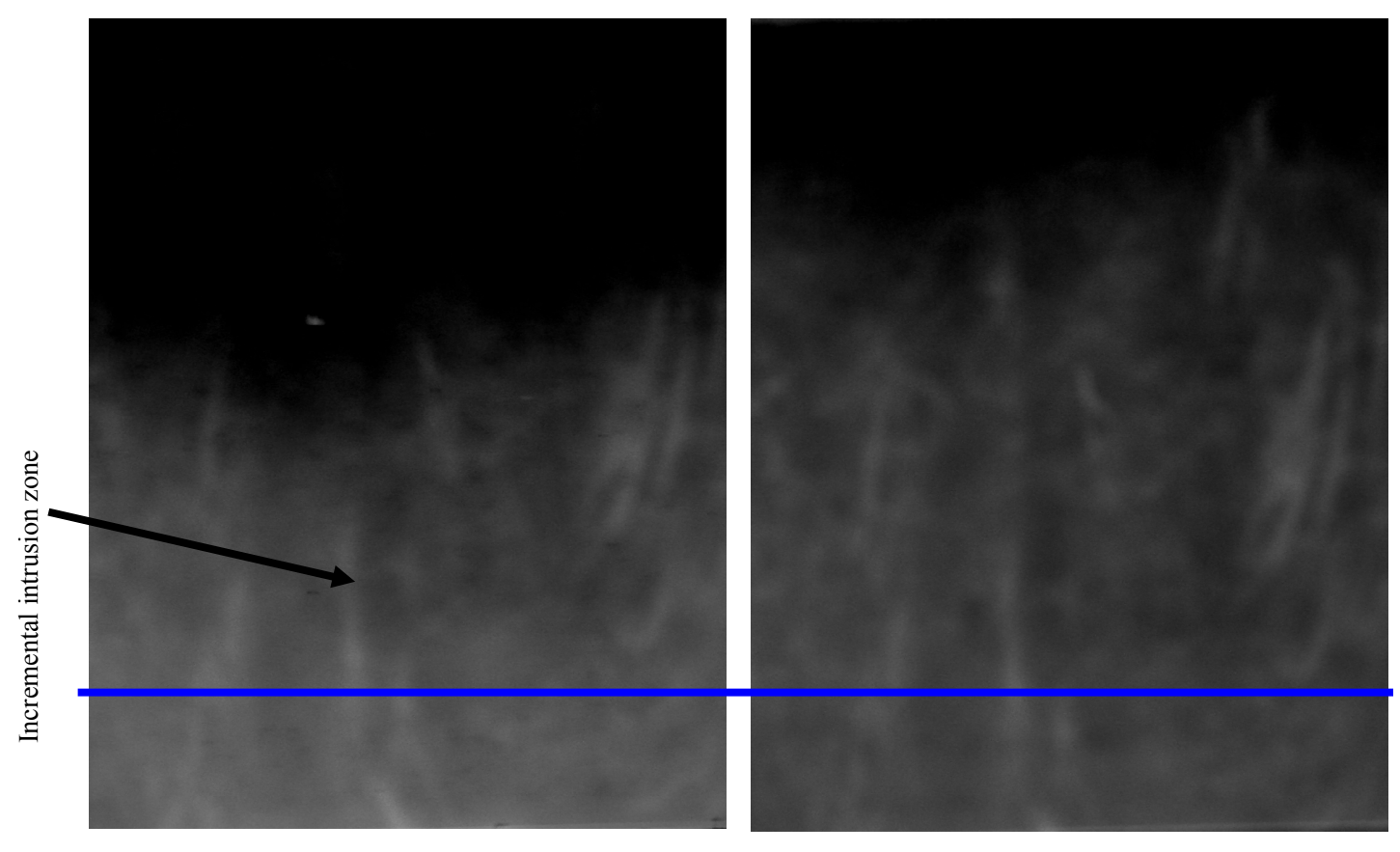

(c)

(d)

Figure 2. NR images of KAB 1 for (a) $5 \mathrm{~min}$ and (b) $10 \mathrm{~min}$ water absorption. NR images of KAB 1 for (c) $15 \mathrm{~min}$ and (d) 20 min water absorption.

$$
I=I_{0} e^{-\mu x}
$$

where, $e=$ base of natural logarithms, $x=$ thickness of an object, $\mu=$ linear neutron attenuation coefficient, $I$ and $I_{0}$ are the neutron intensity after passing through the object and the neutron intensity incident on the object, respectively.

The mathematical expression for the optical density [16] at a point of the film/NR image, $D$ is given by:

$$
D=\ln \left(A_{0} / A\right)
$$

Here, $A_{0}=$ response of densitometer without the sample image and $A=$ response of densitometer with the sample image. 


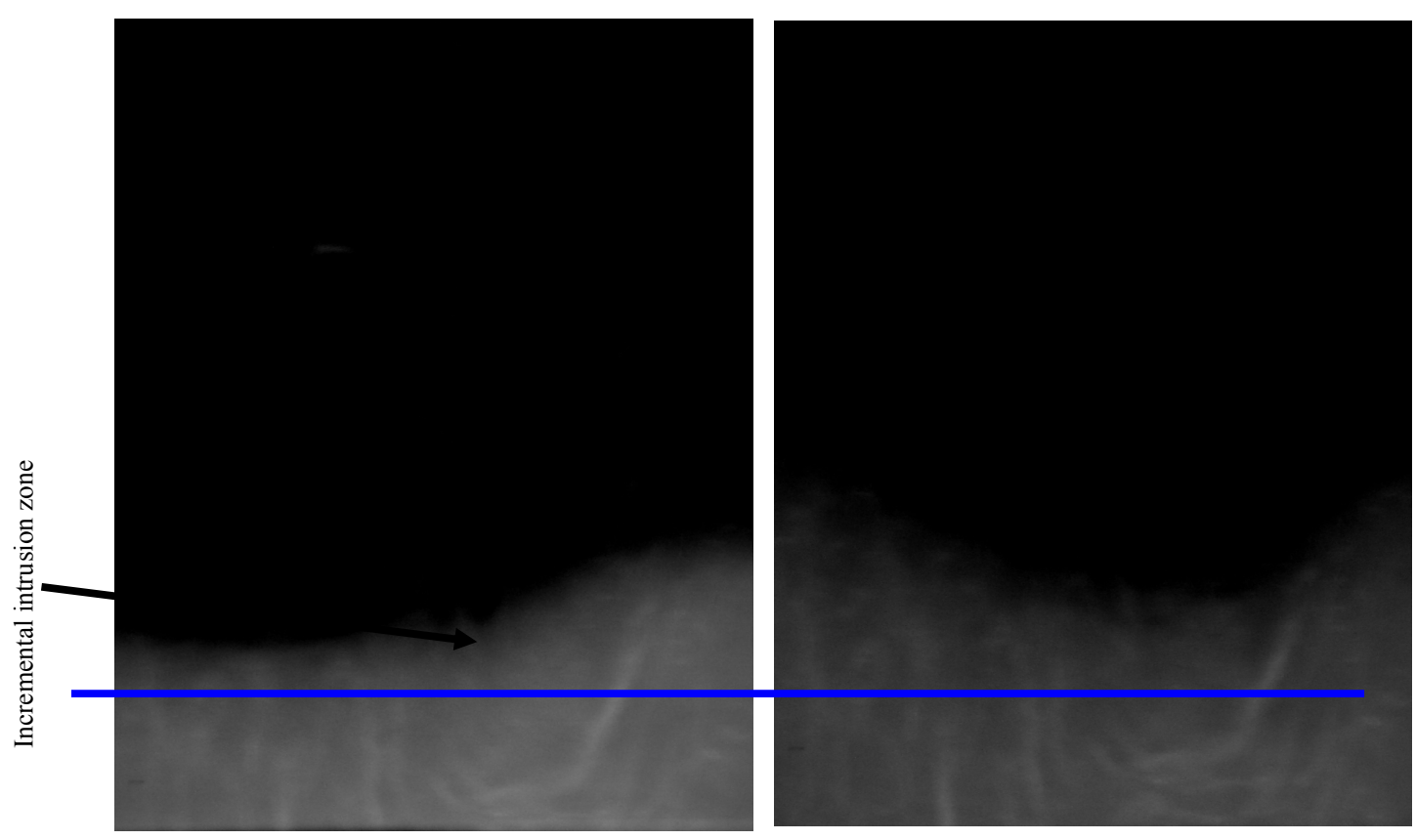

(a)

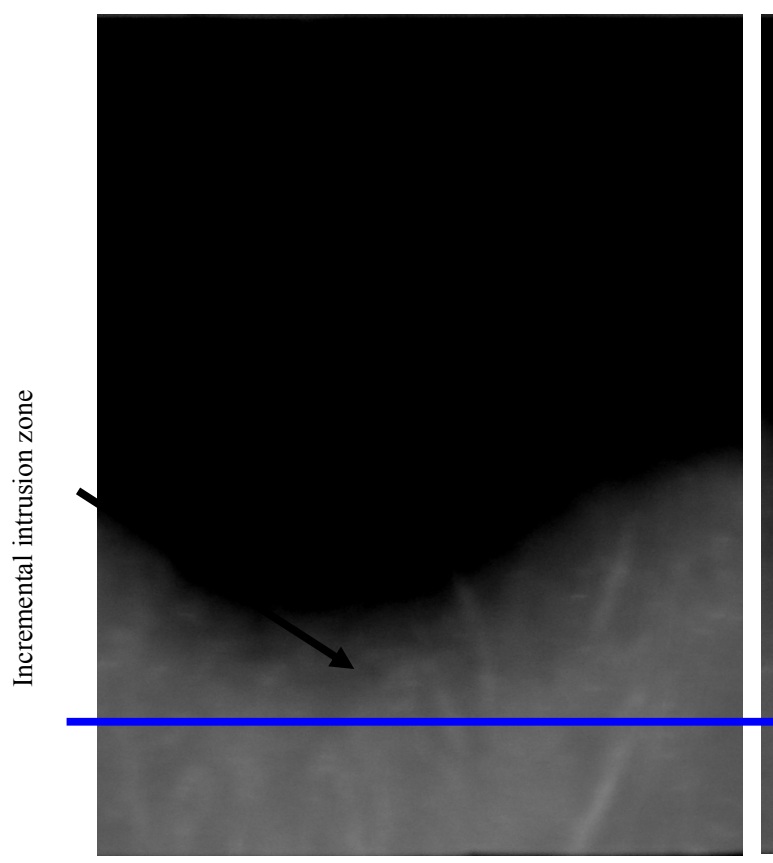

(c)

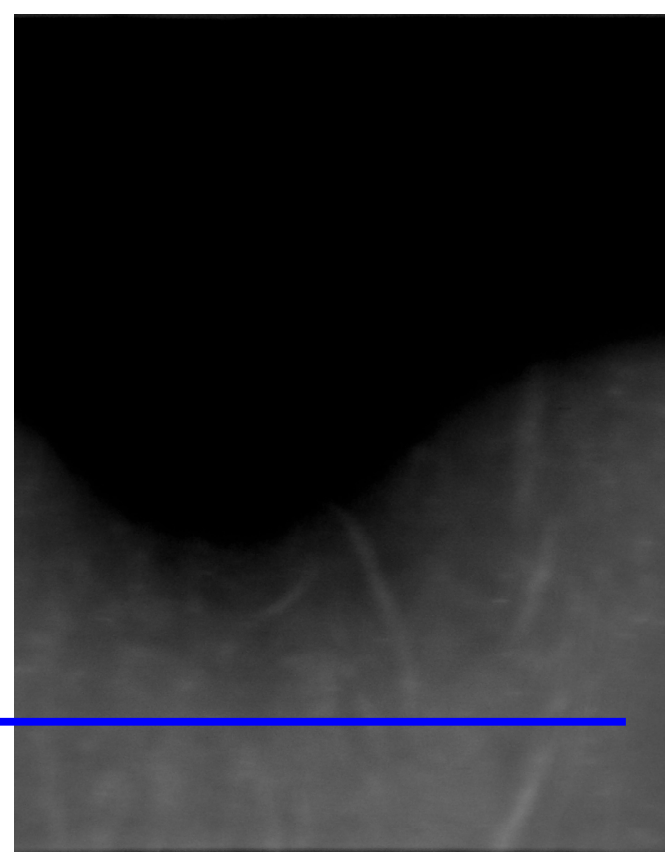

(d)

Figure 3. NR images of KAB 2 for (a) 5 min and (b) 10 min water absorption. NR images of KAB 2 for (c) 15 min and (d) 20 min water absorption.

The density of film is measured with an optical densitometer (Model 07-424, S-23285, Victoreen Inc. USA) [5]. A small beam of light from the light source passes through the film area which is measured by densitometer. On the other side of the film, a light sensor (photocell) converts the penetrated light into an electrical signal. A special circuit performs a logarithmic conversion on the signal and displays the results in density units. The primary use of densitometers in a clinical facility is to monitor the performance of film processors. Actually, optical density is the darkness, or opaqueness, of a transparency film and is produced by film exposure and chemical processing. An image contains areas with different densities that are viewed as various shades of gray. 


\subsection{Gray Value}

The visual appearance of an image is generally characterized by two properties such as brightness and contrast. Brightness refers to the overall intensity level and is therefore influenced by the individual gray-level (intensity) values of all the pixels within an image. Since a bright image (or sub image) has more pixel gray-level values closer to the higher end of the intensity scale, it is likely to have a higher average intensity value. Contrast in an image is indicated by the ability of the observer to distinguish separate neighboring parts within an image. This ability to see small details around an individual pixel and larger variations within a neighborhood is provided by the spatial intensity variations of adjacent pixels, between two neighboring sub images, or within the entire image. Thus, an image may be bright (due to, for example, overexposure or too much illumination) with poor contrast if the individual target objects in the image have optical characteristics similar to the background. At the other end of the scale, a dark image may have high contrast if the background is significantly different from the individual objects within the image, or if separate areas within the image have very different reflectance properties.

Although the intensity distribution within any real-life image is unlikely to be purely sinusoidal, these definitions provide a basis for comparison. For example, an image that contains pixels with brightness values spread over the entire intensity scale is likely to have better contrast than the image with pixel gray-level values located within a narrow range. The relationship between the intensity spread at the pixel level and the overall appearance of an image provides the basis for image enhancement by gray-level transformation. The terms gray value and intensity are used synonymously to describe pixel brightness. Actually, the specific relationship between the shades of gray or density and exposure depends on the characteristics of the film emulsion and the processing conditions. This gray value is measured using image analysis software Image $\mathrm{J}$ [35].

\section{Results and Discussions}

In the present investigation NR techniques has been adopted to study internal defects such as in-homogeneity, porosity/voids, initial rapid absorption (IRA), water penetrating rate/behavior and incremental intrusion area of automated machine made environmentally friendly KAB bricks. Automated machine made environmentally friendly bricks industry (made by Hybrid Hoffman Kiln method) is established very recently in Bangladesh. The NR techniques allowed us to comment on the quality of this type of brick samples from the measurement of the gray value/optical densities of their neutron radiographic images.

\subsection{Porosity/Voids and Homogeneity of the Samples}

The quality of a brick samples depends on the proper distribution of the contents, porosity, hardiness, water absorption behavior etc. in the sample. In this section, porosity, elemental distribution of the samples has been studied by measuring gray value/intensity from the neutron radiographic images of each sample. Variation of gray values of the radiographic images of the samples indicates that the constituent components of the samples are not uniformly distributed and having internal porosity.

The Figure 4 shows the gray value versus pixel distance plots of radiographic image of the KAB sample. The gray value has been obtained by drawing line profile of $1056 \times 1600$ pixel area on the radiographic images of an object. From this figure it is observed that in most of the places the variation of gray value is not regular manner for KAB 1 but in few places it is regular. It is also observed that KAB 1 sample is not perfectly homogeneous and contains little porosity because of irregularity of gray value. In the same figure for KAB 2, it is observed that variation of gray value in most of the pixel point is slightly irregular in nature. This shows that most of the regions for $\mathrm{KAB} 2$ is homogeneous and small region is inhomogeneous. Small variation of gray value/intensity indicates the presence of less internal porosity of that place/area.

\subsection{Water Penetrating Height at Different Immersion Time of the Samples}

\section{KAB 2}

Water penetrating/rising behavior of the KAB 2 sample at different immersion time such as 5, 10, 15, 20 minutes is shown in Figure 5. From these graph it is observed that due to 5 minutes immersion water rises in upward direction is $2.6 \mathrm{~cm}$ and $4 \mathrm{~cm}$ through two edges and $3 \mathrm{~cm}$ at the middle side. In case of 10 minutes, penetrating of water at the middle place is $4 \mathrm{~cm}$ and through the edges this penetration is about $6-6.5 \mathrm{~cm}$. For 15 minutes water immersion, the water uptake is $4 \mathrm{~cm}$ at middle and at two edges the water uptake is $6.4-6.6 \mathrm{~cm}$. For 20 minutes, water uptake is $5 \mathrm{~cm}$ at middle and at two edges is $7-8 \mathrm{~cm}$. From above investigation it shows that at first 5 minutes the water uptake through the middle is very higher than that of 10,15 and 20 minutes. Except for first 5 minutes water immersion, water rises through the two edges is higher than the middle part.

KAB 1 


\section{Homogeneity Measurement}

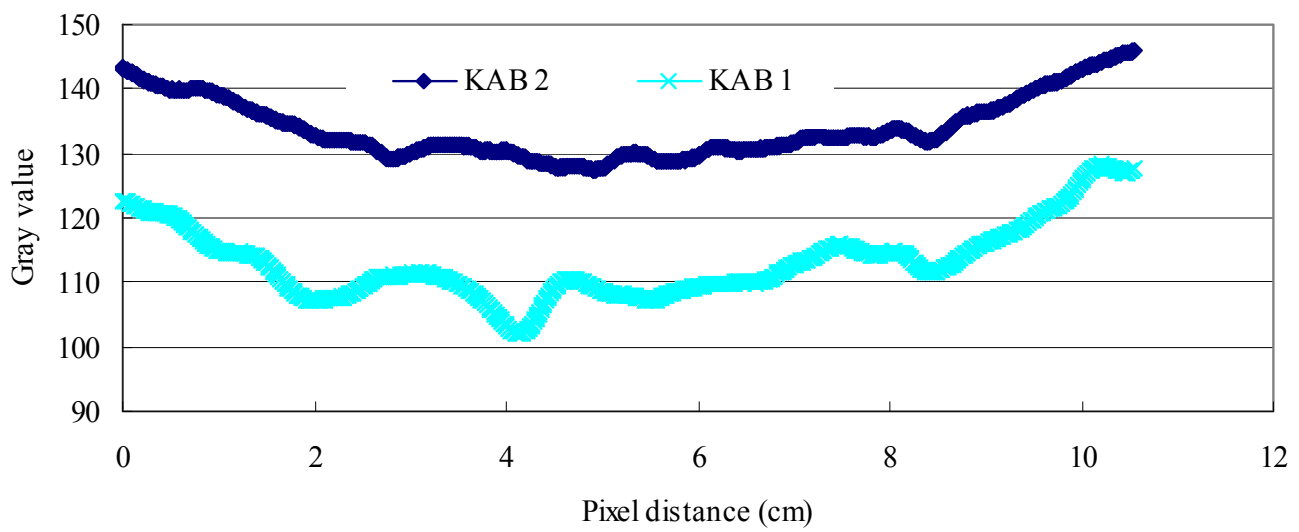

Figure 4. Gray value vs. pixel distance curve.

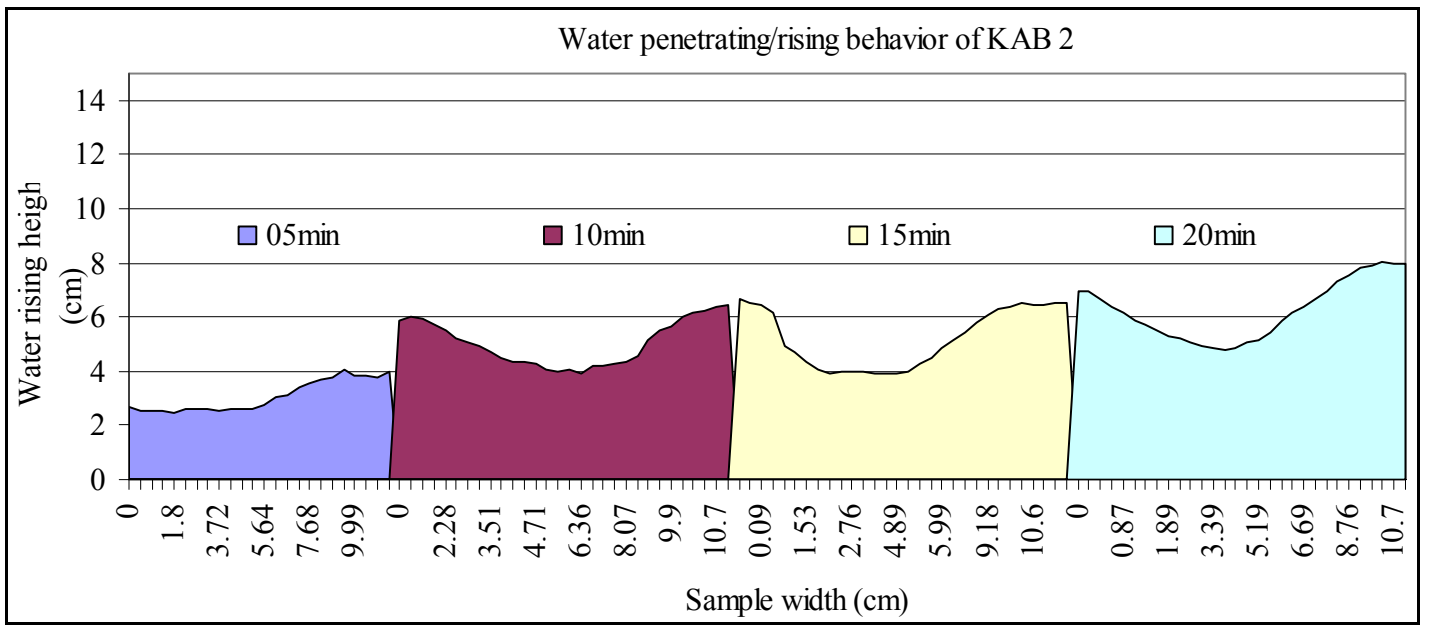

Figure 5. Water penetrating height at different immersion time for KAB 2.

Water penetrating height through the middle zone for $\mathrm{KAB} 1$ sample at $5,10,15$ and 20 minute is $5 \mathrm{~cm}, 8.1 \mathrm{~cm}$, $8.4 \mathrm{~cm}$ and $10.6 \mathrm{~cm}$ (Figure 6), respectively. In that case the water rising through the two edges and the middle is almost same for individual immersion case. The relation of incremental intrusion area which is indicated in the Figures 2 and 3 of neutron radiographic images of the $\mathrm{KAB}$ samples at different immersion time is directly related to the IRA.

\subsection{Determination of Incremental Intrusion Zone and Black/Gray Area}

In the Figures $\mathbf{2}$ and $\mathbf{3}$ is indicating the incremental intrusion zone i.e., water is entering into a zone/place without encroachment and also shows the blue straight line. This blue line separates the actual immersion zone and the incremental intrusion zone of the immersed samples. Lower zone of the blue line is the actual immersion zone and the upper zone indicates the incremental im- mersion zone of the immersed samples. After irradiation of the test (wet) samples KAB $1 \&$ KAB 2, obtained the radiographic images of the wet samples by following the procedure (f) cited in the experimental part on neutron radiographic/Agfa structurix D4DW film as a latent image using neutron radiography method. For visualize this image it is transferred to the PC using high resolution camera and is viewed in the computer screen by the image analysis software Image $\mathrm{J}$. With the help of this software, the total pixel distance corresponds to the total breath/length/height of the sample is calculated along $\mathrm{x} / \mathrm{y}$-axis. From that measurement, the number of pixels/cm breath or length or height of the sample is found. In the present investigation, the actual water length in a pan is $2 \mathrm{~cm}$. So, by subtracting the actual water absorption zone (height, $2 \mathrm{~cm}$ ) from the total water absorption zone of the immersed sample, incremental intrusion zone is found. This subtraction is done by the image analysis software. But, black area and gray area can clearly be 


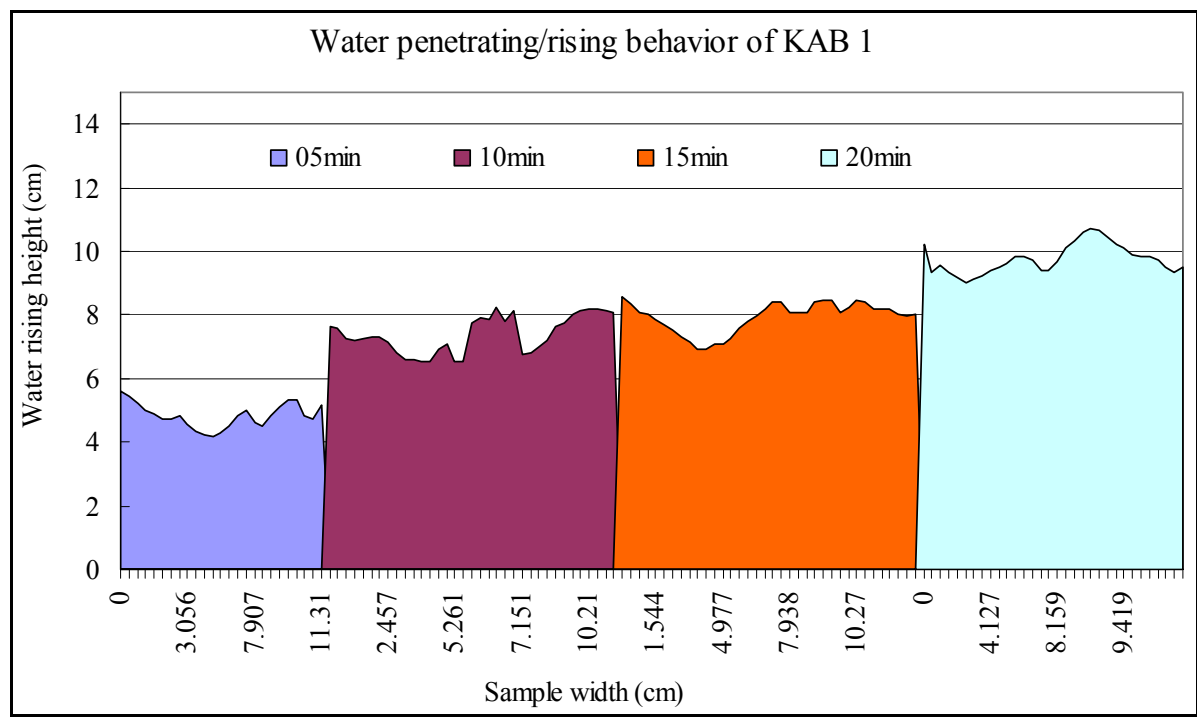

Figure 6. Water penetrating height at different immersion time for KAB 1.

distinguished only by taking radiographic images of the test sample with the help of neutron radiography (NR) method and the image analysis software. Because, Neutron radiography is a process of making a picture of the internal details of an object by the selective absorption of a neutron beam by the object and is a very efficient tool to enhance investigations in the field of non-destructive testing (NDT) as well as in many fundamental research applications. On the other hand, it is suitable for a number of tasks and impossible for conventional X-ray radiography. The advantage of neutrons compared to X-rays is the ability to image light elements (i.e. with low atomic numbers) such as hydrogen, water, carbon etc and can be distinguished gray area/black area of the radiographic image of the sample taken by the neutron radiography method.

\subsection{Water Penetrating Behavior}

Weng et al. studied that water absorption decreased significantly when the temperature increased due to the formation of the amorphous phase at high firing temperature. During the manufacturing time if the clay mixture absorbs more water, brick exhibits a larger pore size, resulting in a lower density. Depending on the $\mathrm{H}_{2} \mathrm{O}$ absorption time of brick, observe differences in capillary absorption [36]. From the present investigation it also shows that the water rising/penetrating behavior through the different brick samples is like as stair, capillary, wave, zigzag shape. The resulting shape of the penetrating water into the different brick sample is shown in Figures 5 and 6.

\subsection{Initial Rapid Absorption (IRA)}

It is the measurement of the absorption rate that water is absorbed by a porous solid. It is related to the durability, porosity, pore size distribution and water absorption. It is sometimes called rising damp. The quantity, sizes and connection of pores influence the absorption rate of the brick. The IRA is reported in units of $\mathrm{g} /\left(30 \mathrm{in}^{2} \cdot \mathrm{min}\right)$ [37]. In the present case, IRA is measured in units of $\mathrm{gm} /$ $\mathrm{cm}^{3} / \mathrm{min}$. Robinson [37] described three stages of capillary absorption. IRA stage is one of them. The results of IRA measurement are shown in Figure 7.

In the case of KAB 2, the initial rapid absorption of water is less and for KAB 1 it is higher than KAB 2. At a glance the IRA for KAB brick sample can be written as $\mathrm{KAB} 2<\mathrm{KAB} 1$. Low values of water absorption obtained in this study indicate that the clay bricks produced were poorly porous. Internal structure of the brick is expected to be intensive enough to avoid intrusion of water [36].

Dr. Robinson [37] found a relationship between capillarity and freeze thaw durability. He stated that durability is a function of the pore structure and the nature of the fired bond. On the other hand, capillary absorption measures how well water moves through the brick, then it must have some bearing on the efflorescence potential. Theoretically, the rate of capillary absorption influences the bond between brick and mortar (mixture of lime, water and sand). York dale did not believe that there was a direct relationship between IRA and performance and did not feel that IRA should be included in ASTM specifications. This disagreement is probably related to the lack of information contained in the IRA measurement. Workmanship plays such a large role in the quality of masonry that it is hard to definitively identify the influence of other factors. Rising damp and moisture transfer through masonry. For a particular type of brick which suggests 


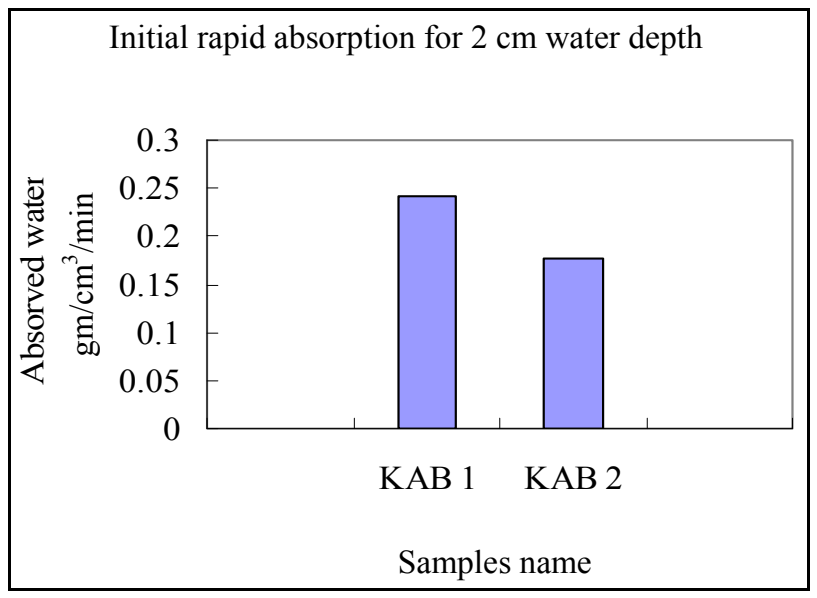

Figure 7. IRA measurement for KAB samples.

that the connectivity and orientation of pores also play a large part in the movement of water in the pores [37].

\section{Conclusions}

The quality of a brick depends on the proper distribution of the contents/homogeneity, porosity, water penetrating behavior etc. in the sample. From the optical density measurement (Figure 8), it is observed that the optical density curve for KAB 2 sample is almost straight and for $\mathrm{KAB} 1$, it shows far from straight line. From the points of optical density measurement, porosity, homogeneity, IRA and water penetrating behavior of view, it is pointed out that KAB is in good quality. The specific relationship between the shades of gray or density and exposure depends on the characteristics of the film emulsion and the processing conditions.

This absorption rate for KAB 2 is lower than that of $\mathrm{KAB} 1$ and the water absorption increases with time gradually. Figure 9 shows the water absorption characteristics of the samples. This indicates that after 5 minutes' immersion the absorption rate is very slow and becomes steady during long immersion time. In the case of KAB sample, steady time is higher. With higher steady time, slow absorption rate indicates the good quality. Many authors $[38,39]$ studied that this absorption depends on submersion time, firing temperature and firing time. Few authors [40] investigate that when the mixture absorbs more water, brick exhibits a larger pore size, resulting in a lighter density.

\section{Acknowledgements}

Authors would like to thanks to the production manager, Kapita auto bricks limited, Joypura, Dhamrai, Dhaka, Bangladesh for supply the sample and to the Ministry of Science \& Technology for their financial aid in order to

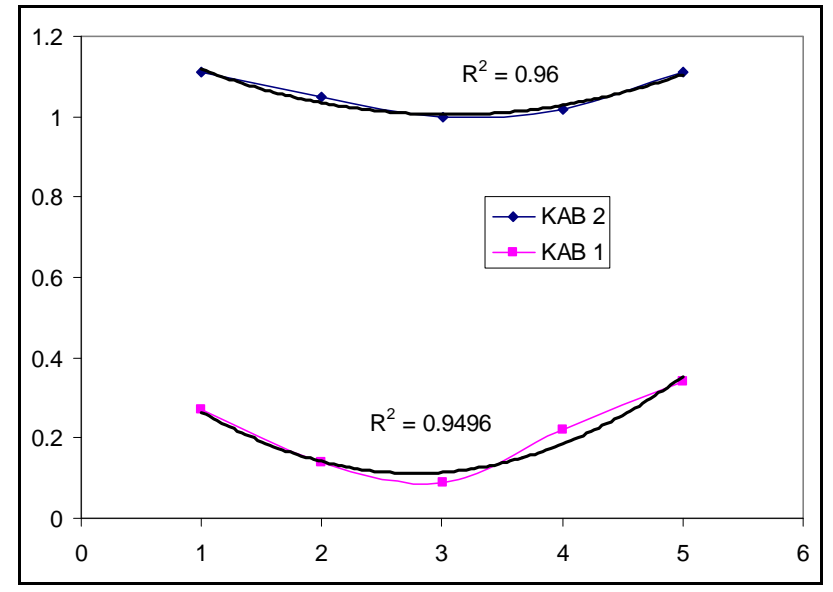

Figure 8. Optical densitometric measurement of different NR images.

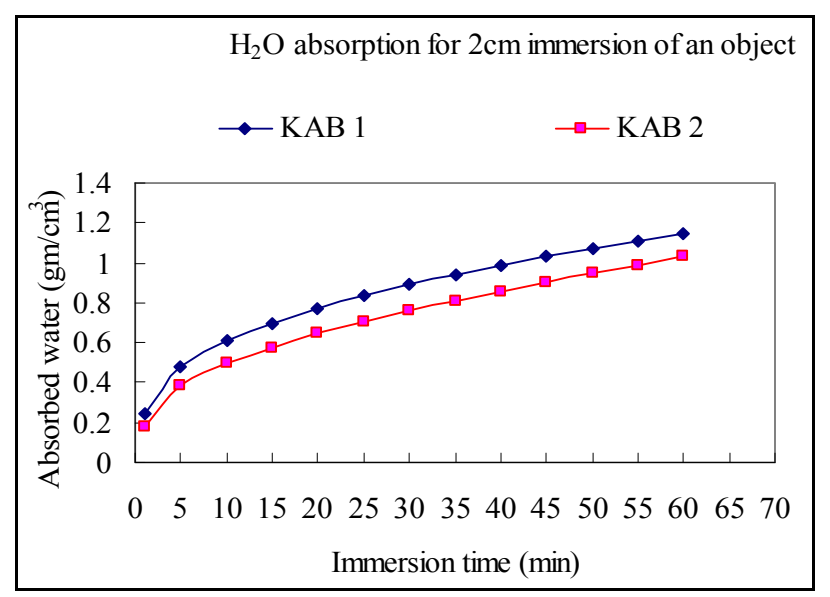

Figure 9. Water absorption rate of the sample (samples are immersed in water only $2 \mathrm{~cm}$ ).

collection/completion of this work.

\section{REFERENCES}

[1] H. Berger, "Neutron Radiography," Elsevier, Amsterdam, 1964.

[2] P. Von der Hardt and H. Rotterger, "Neutron Radiography Hand Book," D. Reidel Publishing Company, Dordrecht, 1981. http://dx.doi.org/10.1007/978-94-009-8567-4

[3] M. M. Rahman, S. Saha, M. N. Islam, M. K. Alam, A. K. M. A. Rahman and S. M. Azharul Islam, "A Study of the Morphological Change in Plant Pod by Using Neutron Radiography Technique," Journal of African Review of Physics, Vol. 8, 2013, pp. 239-242.

[4] J. M. Cimbala, D. E. Hughes, S. Levine and D. Sathianathan, "Application of Neutron Radiography for Fluid Flow Visualization," Nuclear Technology, Vol. 81, No. 3, 1988, pp. 435-445.

[5] M. N. Islam, M. M. Rahman, S. M. A. Islam and M. A. Zaman, "Neutron Radiographic Investigation of the Qual- 
ity of Some Rubber Samples," Indian Journal of Pure and Applied Physics, Vol. 38, 2000, pp. 675-680.

[6] M. K. Alam and M. A. Khan, "Study of Water Absorption and Internal Defects in Jute Reinforced Biopol Composite Using Digital Neutron Radiography Technique," Journal of Bangladesh Academy of Sciences, Vol. 30, No. 1, 2006, pp. 29-37.

[7] C. Renfrew and P. Bahn, "Archaeology: Theories, Methods and Practice," Thames and Hudson, New York, 1996.

[8] P. Rice, "Pottery Analysis: A Sourcebook," University of Chicago Press, Chicago, 1987.

[9] M. K. Alam, "Comparative Study of Internal Defects in Ceramic Products Using CCD-Camera Based Digital Neutron Radiography Detector," Bangladesh Journal of Scientific and Industrial Research, Vol. 40, No. 3-4, 2005, p. 169.

[10] M. K. Alam, M. N. Islam and M. A. Zaman, "Study of Internal Defects and Water Absorption Behavior of Single Layer Italian Tiles Using Neutron Radiography Facility of 3 MW TRIGA MARK II Research Reactor," Journal of Bangladesh Academy of Sciences, Vol. 31, No. 2, 2007, pp. 213-222.

[11] M. N. Islam, M. K. Alam, M. A. Zaman, M. H. Ahsan and N. I. Molla, "Application of Neutron Radiography to Building Industries," Indian Journal of Pure and Applied Physics, Vol. 38, 2000, pp. 348-354.

[12] M. K. Alam, M. A. Khan and E. H. Lehmann, "Comparative Study of Water Absorption Behavior in Biopol and Jute Reinforced Biopol Composite Using Neutron Radiography Technique," Journal of Reinforced Plastics and Composites, Vol. 25, No. 11, 2006, pp. 1179-1187. http://dx.doi.org/10.1177/0731684406066365

[13] M. N. Islam, M. A. Khan, M. K. Alam, M. A. Zaman and M. Matubayashi, "Study of Water Absorption Behavior in Wood Plastic Composite by Using Neutron Radiography Technique," Polymer-Plastics Technology and Engineering, Vol. 42, No. 5, 2003, pp. 925-934. http://dx.doi.org/10.1081/PPT-120025004

[14] A. H. Bouma, "Methods for the Study of Sedimentary Structures," John Wiley and Sons, New York, 1969, p. 140.

[15] P. M. Norris, J. S. Brenizer, D. A. Paine and D. A. Bostain, "Measurements of Water Deposition in Aerogel by Neutron Radiography," Proceedings of 5th World Conference on Neutron Radiography, Berlin, 17-20 June 1996, p. 602.

[16] A. A. Harms and D. R. Wyman, "Mathematics and Physics of Neutron Radiography," D. Reidel Publishing Company, Holland, 1986, p. 22. http://dx.doi.org/10.1007/978-94-015-6937-8

[17] B. Illerhaus, "Proc. Seminar Computer Tomographie: Stand der Technik und Zukunftsaussichten," Family Readiness Group, Stuttgart, Vol. 29, 1988, p. 15.

[18] G. Pfister, A. K. Schatz, C. Siegel, E. Steichele, W. Waschkowski and T. Bucherl, "Nondestructive Testing of Materials and Components by Computerized Tomography with Fast and Thermal Reactor Neutrons," Nuclear
Science and Engineering, Vol. 110, No. 4, 1992, pp. $303-$ 315.

[19] ASTM-E545-05, "Standard Test Method for Determining Image Quality in Direct Thermal Neutron Radiographic Examination," 2010.

http://www.astm.org/Standards/E545.htm

[20] H. P. Leeflang and J. F. W. Margraf, "Detection of Corrosion on Air Craft Components by Neutron Radiography," Proceedings of the 4th World Conference on NR, Sandiego, 10-16 May 1992, pp. 161-172.

[21] S. Prasertsan and T. Theppaya, "A Study toward Energy Saving in Brick Making: Part 1-Key Parameters for Energy Saving," International Energy Journal, Vol. 17, No. 2, 1995, pp. 145-156.

[22] J. M. Bhatnagar and R. K. Goel, "Thermal Changes in Clay Products from Alluvial Deposits of the IndoGangetic Plains," Construction and Building Materials, Vol. 16, No. 2, 2002, pp. 113-122.

[23] G. Cultrone, E. Sebastian, K. Elert, M. J. Torre, O. Cazalla and C. Rodriguez-Navarro, "Influence of Mineralogy and Firing Temperature on the Porosity of Bricks," Journal of the European Ceramic Society, Vol. 24, No. 3, 2004, pp. 547-564.

[24] L. Mbumbia, A. M. Wilmars and J. Tirlocq, "Performance Characteristics of Lateritic Soil Bricks Fired at Low Temperatures: A Case Study of Cameroon," Construction and Building Materials, Vol. 14, No. 3, 2000, pp. 121131. http://dx.doi.org/10.1016/S0950-0618(00)00024-6

[25] W. J. MC Burrey, "The Effect of Strength of Brick on Compressive Strength of Brick Masonary Process," Vol. 2, ASTM, West Conshohocken, 1970, p. 28.

[26] "Manufacturing, Classification and Selection of Brick, Manufacturing Part I," Brick Industry Association, Reston, 1986.

[27] O. Kayali and K. J. Shaw, "Manufactured Articles from Fly Ash," Patent no.PCT/AU03/01533, Australia, International Patent no. PCT/AU02/00593, European Patent Registration, R. Dhir, T. Dhir and J. Halliday, Eds., Publisher.

[28] C. Renfrew and P. Bahn, "Archaeology: Theories, Methods and Practice," Thames and Hudson, New York, 1996.

[29] P. Rice, "Pottery Analysis: A Sourcebook," University of Chicago Press, Chicago, 1987.

[30] S. Bhatnagar and R. K. Goel, "Thermal Changes in Clay Products from Alluvial Deposits of the Indo-Gangetic Plains," Construction and Building Materials, Vol. 16, No. 2, 2002, pp. 113-122. http://dx.doi.org/10.1016/S0950-0618(01)00031-9

[31] S. L. Marrusin, "Interrior Fissures and Microstructure of Shale Brick," American Ceramic Society Bulletin, Vol. 64, No. 5, 1985, pp. 674-678. (Turkish Standards Institutions, Ankara, 1979).

[32] M. A. Rahman, J. Podder and I. Kamal, "Neutron Radiography Facility in Bangladesh Research Reactor," Proceedings of the 3rd World Conference on Neutron Radiography (NR), Osaka, 14-18 May 1989, pp. 179-185. 
[33] M. N. Islam, M. M. Rahman, M. H. Ahsan, A. S. Mollah, M. M. Ahasan and M. A. Zaman, "A Study of Neutron Radiography Parameters at the Tangential Beamport of the 3 MW TRIGA Research Reactor of AERE, Savar," Jahangirnagar University Journal of Science, Vol. 19, 1995, p. 181-187.

[34] H. I. Bjelkhagen, "Silver-Halide Recording Materials," Springer Verlag, 1993, pp. 128-151. http://dx.doi.org/10.1007/978-3-540-47593-4

[35] T. J. Collins. "Image J for Microscopy," BioTechniques, Vol. 43, No. S1, 2007, pp. S25-S30. http://dx.doi.org/10.2144/000112517

[36] C. H. Weng, D. F. Lin and P. C. Chiang, "Utilization of Sludge as Brick Materials," Advances in Environmental Research, Vol. 7, No. 3, 2003, pp. 679-685.
http://dx.doi.org/10.1016/S1093-0191(02)00037-0

[37] J. Sanders and J. Frederic, "Capillary-A New Way to Report IRA (initial rate of absorption)," Structural Clay Products Division Meeting, The National Brick Research Center, Gettysburg, 2-4 May 2011, pp. 1-24.

[38] “Clay Bricks (Wall Tile), TS 704," Turkish Standards Institution, Ankara, 1979.

[39] "Solid Bricks and Vertically Perforated Bricks, TS 705," Turkish Standards Institution, Ankara, 1975.

[40] S. Karaman, S. Ersahin and H. Gunal, "Firing Temperature and Firing Time Influence on Mechanical and Physical Properties of Clay Bricks," Journal of Scientific \& Industrial Research, Vol. 65, No. 2, 2006, pp. 153-159. 